\title{
Cloud Computing - European Perspectives on impacts and potentials of Cloud Computing and Social Network Sites
}

\section{Interim Report - Phase I}

Deliverable No.1 of the

STOA Project "Potential and Impacts of Cloud Computing Services and Social Network Sites"

Commissioned by STOA and carried out by ETAG

Order Form No. IP/A/STOA/FWC/2008-096/LOT4/C1/SC8

Ref.: Framework Contract No. IP/A/STOA/FWC/2008-096/LOT4

Paper prepared by

Mr Timo Leimbach (Fraunhofer ISI)

Mr. Arnd Weber (ITAS)

Mr Michael Friedewald (Fraunhofer ISI)

Mr René Koenig (ITAS)

Mr Michael Nentwich (ITA)

Mr Leonhard Hennen (ITAS)

Mr Stefan Strauß (ITA)

Mr Jakob Nielsen Skødt (DBT)

\section{European Technology Assessment Group}

- Institute for Technology Assessment and Systems Analysis (ITAS), Karlsruhe

- Danish Board of Technology (DBT), Copenhagen

- $\quad$ Catalan Foundation for Research and Innovation (FCRI), Barcelona

- Fraunhofer Institute for Systems and Innovation Research (ISI), Karlsruhe

- Institute Society Technology (IST), Brussels

- Institute of Technology Assessment (ITA), Vienna

- $\quad$ Rathenau Institute, The Hague

- Technology Centre AS CR, Prague

Contact:

Dr Leonhard Hennen (Co-ordinator)

Institute for Technology Assessment and Systems Analysis; Karlsruhe Institute of Technology

c/o Helmholtz-Gemeinschaft

Ahrstr. 45, D-53175 Bonn

Leonhard.Hennen@kit.edu 


\section{Project Description}

Contract number IP/A/STOA/FWC/2008-96/LOT4/C1/SC8

The project is being carried out by the

Fraunhofer Institute for Systems and Innovation Research (ISI), Karlsruhe

(project co-ordinator);

together with the Institute of Technology Assessment (ITA), Vienna; the Institute for Technology Assessment and Systems Analysis (ITAS), Karlsruhe; and the Danish Board of Technology (DBT), Copenhagen, as members of ETAG.

Project Leader: Timo Leimbach, Fraunhofer ISI

Authors:

Mr Timo Leimbach (Fraunhofer ISI)

MrMichael Friedewald (Fraunhofer ISI)

MrMichael Nentwich (ITA)

Mr Stefan Strauß (ITA)

Mr Leonhard Hennen (ITAS)

Mr Arnd Weber (ITAS)

Mr. René Koenig (ITAS)

Mr.Jakob Nielsen Skødt (DBT)

Members of the European Parliament in charge: Malcom Harbour

STOA staff in charge: Peter Ide-Kostic

Submission date:

June15 $5^{\text {th }}, 2012$ 


\section{Contents}

General I nformation

Main Part: Cloud Computing Services and Social Network Websites state-of-the-art in research and practice

1. Cloud Computing and Social networks: Definitions and recent Policy activities

1.1. Definitions 6

1.2. Cloud Computing 6

1.2.1. Distributed Computing 8

1.2.2. Grid Computing 8

1.2.3. Virtualization 8

1.2.4. Utility computing 8

1.2.5. Ubiquitous computing and related concepts 8

1.2.6. Social Network Sites 9

1.2.7. Summary 9

1.3. Recent policy activities regarding Cloud Computing and

1.3.1. Activities on the European level 10

1.3.2. Activities on the EU Member State level 11

1.3.3. I nternational activities 12

2. Major research perspectives $\quad 14$

2.1. Foundations of Cloud Computing 14

2.1.1. Evolution of Cloud Computing concepts and technologies 14

2.1.2. Challenges and opportunities to Cloud Computing in Europe 15

2.2. I mpacts of Cloud Computing 17

2.2.1. Economic and social impacts of Cloud Computing 17

2.2.2. Security, privacy, intellectual property/ copyright and
other legal issues of cloud computing

2.3. Social Network Sites $\quad 22$

2.4. Enterprise Social Software 24

3. Main research questions $\quad 27$

$\begin{array}{ll}\text { References } & 29\end{array}$

ANNEX: Project plan “Cloud Computing and Social Networks” 34

Project phases in detail $\quad 34$

Deliverables and dates $\quad 40$ 


\title{
Selected Abbreviations
}

\author{
AaaS Applications as a Service \\ CC Cloud Computing \\ DAE Digital Agenda for Europe \\ IaaS Infrastructure as a service \\ ICT Information and Communication Technologies \\ MIC Ministry of Internal Affairs and Communication (Japan) \\ NIST National Institute of Standards and Technology \\ PaaS Platform as a service \\ SME $\quad$ Small and medium sized enterprises \\ SNS Social Network Sites
}




\section{GENERAL I NFORMATI ON}

This document is the result of the consultation phase of the STOA-project "Potential and Impacts of Cloud Computing Services and Social Network Sites". It addresses in the first place cloud computing and furthermore social network sites. While Cloud computing (CC) has broad implications for all areas of society and business applications are perhaps crucial for its sustained breakthrough, social network sites (SNS) have their main impact on relationships between private citizens or private citizens and businesses. Beside the impact on the IT industry itself, the development of both is also seen as pivotal for the overall competitiveness of the European economy and society. However, both also pose a number of challenges for enterprises as well as for private citizens. There could be increasing virtualisation of the processing of personal and other sensitive data that is transmitted and stored by commercial providers on servers situated in a location unknown to the costumer. Given these challenges, it is not clear whether both and in particular cloud computing will meet its potential and the high expectations connected to it. Therefore the goal of the project is to analyse this blurry situation and to assess potentials as well as positive and negative impacts for citizens, business and public authorities from a European perspective.

This interim report summarises the results of the first project phase, which lasted from April $15^{\text {th }}$ to June $15^{\text {th }}$ 2012. The main objective of this first project phase was the development of a detailed plan for the next four phases of the project. A preparatory meeting, held in May 2012, and several telephone conferences during the consultation phase with the project partners were very instrumental in discussing and prioritising research themes and issues.

The report itself consists of two parts. The main part presents an introductory overview of the debates on Cloud Computing Services and Social Network Sites and their potentials and impacts for the European society as a whole. Against this background, the main research perspectives of the project are discussed in detail. Finally, the project's research questions are presented. The annex describes the project plan, gives an overview of the project schedule and the deliverables.

An important element of the whole project is the involvement of those MEPs who are particularly interested in the issue of Cloud Computing and Social Network Sites. We are convinced that taking the perspective of these representatives into account will help to generate recommendations that are considered useful by European decision-makers and practitioners. 


\section{MAI N PART: CLOUD COMPUTING SERVICES AND SOCIAL NETWORK WEBSITES - STATE-OF-THE-ART IN RESEARCH AND PRACTI CE}

\section{CLOUD COMPUTING AND SOCIAL NETWORKS: DEFI NITI ONS AND RECENT POLICY ACTIVITIES}

\subsection{Definitions}

In recent years, Cloud Computing (CC) and Social Network Sites (SNS) have become major trends not only in business but also in various other fields of society. Despite of a number of critical issues that are being discussed around these technologies, there is little doubt that they are generally successful and increasing. Due to this positive connotation and the still dynamic development, associations to these technologies are made frequently but not always precisely. This is in particular the case for CC, which has become an extremely popular label for all kinds of Internet-using IT-services. At the same time, different actors have different understandings of the terms, depending on their specific perspective and the technologies themselves keep changing. Therefore, it is hard to find clear-cut and overarching definitions which are neither too wide and vague, nor too narrow and exclusive. To avoid this dilemma, the terms presented below are rather to be seen as emerging concepts than as technically exact definitions. They are not clearly distinct but together they should provide a sufficient understanding of the phenomena in the context of this project.

\subsection{Cloud Computing}

The term "cloud computing" (CC) became popular around 2006 when big companies (such as Google or Amazon) started to use it, but it dates back to 1996 (Regalado 2011). Without using the term itself, the basic idea was prominently pointed out with Sun Microsystems' slogan "the network is the computer" in the early 1990s (McFredries 2008). However, the concept (theoretically and practically) was not widely used before fast broadband connections became generally available. According to a highly-cited definition by the USAmerican National Institute of Standards and Technology (NIST), CC is described as "[...] a model for enabling ubiquitous, convenient, on-demand network access to a shared pool of configurable computing resources (e.g., networks, servers, storage, applications, and services) that can be rapidly provisioned and released with minimal management effort or service provider interaction"(Mell/Grance 2011, p. 2).

This definition is rather inclusive, leaving room for interpretation. Therefore, it is accompanied by a list of "essential characteristics" and other specifications. Moreover, NIST introduces CC as an essential element of intelligent infrastructures, consisting of three layers: "Infrastructure as a Service" (IaaS), "Platform as a Service" (PaaS) and "Software as a Service" (SaaS). 
Table 1: The Cloud Computing Layers

\begin{tabular}{|c|}
\hline User \\
\hline Software as a Service (SaaS) \\
\hline Platform as a Service (PaaS) \\
\hline Infrastructure as a Service (I aaS) \\
\hline Hardware \\
\hline
\end{tabular}

These different types of services, shown in table 1, have varying levels of complexity, which increase from the bottom to the top. IaaS such as Amazon Elastic Compute Cloud simply provides a flexible infrastructure according to the user's needs. PaaS already comes with a platform that helps its users with certain services, for example, the Google App Engine, which supports developers with a web-based interface through which they can host their applications. This gets even more complex on the level of SaaS, where users are merely confronted with the surface of specific software, e.g. Salesforce.com and their solutions for customer relationship management or Google Docs.

When it comes to the provider of the infrastructure, four different cloud models can be differentiated (Mell/Grance 2011):

- The private cloud (1) with an internal infrastructure for a single organization (eventually provided by a third party);

- the community cloud (2) with an infrastructure which is shared by several organizations with certain common concerns (also eventually provided by a third party);

- $\quad$ the public cloud (3) provided by a professional cloud computing service for the general public or business users and

- $\quad$ the hybrid cloud (4), combining models 1-3 (e.g. by using a private cloud and offering available capacities to external customers)

Models 1 and 2 could be found in a similar way already before the era of CC. Their limited breadth also reduces potential risks and benefits: An internal cloud solution for a single corporation is in fact a form of in-house computing (if not outsourced), which only affects this company. At the same time, the customer has much more control over the service than in public cloud models. Therefore, this project focuses especially on models 3 and 4, or a more narrow CC definition which stresses its large scale, externality, abstractness and economics due to sharing with other customers:"A large-scale distributed computing paradigm that is driven by economies of scale, in which a pool of abstracted, virtualized, dynamically-scalable, managed computing power, storage, platforms, and services are delivered on demand to external customers over the Internet."(Foster et al. 2008)

Obviously, CC is not an entirely new concept and builds on a number of already established technologies, such as virtualization, utility computing or distributed computing (Foster et al. 2008; Vaquero et al. 2008; see below) which cannot always be clearly separated from each other. The current hype around CC fuels this confusion, "[...] turning the Cloud into an excessively general term that includes almost any solution that allows the outsourcing of all 
kinds of hosting and computing resources" (Vaquero et al. 2008, p. 50). In order to grasp the societal impact of $\mathrm{CC}$, it is important to remember that it is often used improperly while also acknowledging this excessive usage of the term as an indicator for the significance of the concept.

\subsubsection{Distributed Computing}

Distributed computing can be regarded as an umbrella term for a number of concepts based on parallel computing, i.e. carrying out calculations simultaneously for a shared goal, allowing them to be performed on different processors or computers at the same time. In contrast to basic parallel computing, the different elements of distributed systems may operate more independently from each other (Peleg 2000). While CC is generally a form of distributed computing, this does not necessarily apply vice versa, as distributed computing can already be done locally by a few machines, for example in form of grids.

\subsubsection{Grid Computing}

The term grid computing was coined in the mid-1990s and described the idea of providing computer power on demand by standardizing protocols. Therefore, the principle is more or less identical to CC. As Foster et al. (2008, p. 2) put it, "[...] Cloud Computing not only overlaps with Grid Computing, it is indeed evolved out of Grid Computing and relies on Grid Computing as its backbone and infrastructure support." In contrast to grids, clouds are outsourced to more or less abstract online services, giving users more flexibility but also less control over their data (Myerson 2009). However, it is hard to draw a clear line between grid and cloud computing, since large complex online computer networks have also been described as grids.

\subsubsection{Virtualization}

Virtualization is the decoupling of applications, desktops etc. from physical local hardware by using virtual machines. This allows e.g. for running several operating systems on one computer or server. Although this basic concept itself dates back to the $1960 \mathrm{~s}$, it has recently become increasingly popular for achieving higher efficiency on Internet servers (Sridhar 2009). At the same time, virtualization usually hides the underlying complexity from the user because the desktops, applications etc. appear as if they run on the local machine. Many CC services make use of this technology, e.g. Dropbox which provides regular folders on a local hard drive that is synchronized online with the cloud.

\subsubsection{Utility computing}

Utility computing is the idea to provide computing resources on demand according to individual needs, similar to traditional utilities for water, electricity or telephone and the like. This requires not only the computing infrastructure itself but also mechanisms to meter and bill the services. Therefore, utility computing is not only a technological concept but also a business model and - since it is currently only partly implemented - a vision (Coombes/Siddiqi 2008). CC is a way to realize the idea of utility computing within the current technical and economical limitations.

\subsubsection{Ubiquitous computing and related concepts}

The broad availability of computers and their diffusion in everyday life has brought up a number of concepts, which are often confused and used interchangeably. Mark Weiser 
(1991) coined the term ubiquitous computing when he outlined his vision of "The Computer for the 21st Century". His core idea was to design computers in a way they become invisible to their users, in a form of "embodied virtuality" (ibid., p. 98). Pervasive computing is a similar concept which is frequently used synonymously (e.g. Satyanarayanan 2001), although some argue that there are notable differences which get blurred by the public usage of the terms (Ronzani 2009). CC can be applied in such a context by outsourcing computing resources, thereby giving greater independence from local hardware and more freedom for the human-friendly design of devices. This creates new opportunities for mobile computing, which is today broadly exercised through laptops, netbooks, tablet computers, smartphones etc. Related to such concepts, one can find further ideas, such as the Internet of things which makes physical objects part of the online world (e.g. by using RFID chips).

\subsubsection{Social Network Sites}

Social Network Sites (SNS) offer novel communicative possibilities; above all they link-up its members and map their offline networks. SNS were prominently defined as:"[...] webbased services that allow individuals to (1) construct a public or semi-public profile within a bounded system, (2) articulate a list of other users with whom they share a connection, and (3) view and traverse their list of connections and those made by others within the system"(Boyd/Ellison 2007).

However, this definition is not absolutely precise and one can also find a number of similar terms, which are often used synonymously (e.g. social networks, social network[ing] sites/services/platforms). Depending on the applied definition and its interpretation, various services can be categorized under this label, evidently Facebook, LinkedIn, MySpace etc., but perhaps also micro blogging services (e.g. Twitter), video platforms (e.g. YouTube) or social bookmarking services (e.g. delicious). Moreover, SNS can be differentiated further, e.g. according to their target group. Then we can identify, for instance, science-specific SNS like ResearchGate (Nentwich/König 2012) or restricted business oriented SNS like Yammer, Communote and other services categorized as enterprise software.

SNS is a typical example for a more social and participatory Internet which has been labelled as Web 2.0. While the term itself was already used 1999, it only became popular with an article by $O$ 'Reilly (2005), which described the shift into a platform-based web.

\subsubsection{Summary}

With regard to $\mathrm{CC}$, we suggest focusing our investigation mainly on the business use of computing resources on the Internet and therefore use the following definition of $\mathrm{CC}$ in our project: on-demand network access to an external, shared pool of configurable computing resources. With regardto SNS, we focus on web-based services such as Facebook and Yammer, where individuals can provide information and share it with other users. Thus we will focus on services which use shared remote resources for handling potentially sensitive data, such as business secrets or personal data, which makes those services as just defined a worthwhile topic of technology assessment. 


\subsection{Recent policy activitiesregarding Cloud Computing and Social networks}

Due to the high importance of both technologies for the economic and social development, it is no wonder that they are one major focus of policy activities in the field of ICT all over the world.

\subsubsection{Activities on the European level}

In the aftermath of the EU 2020 strategy the European Commission has launched seven flagship initiatives of which one is dedicated to the topic of the digital development in the European Union. The Digital Agenda for Europe (DAE) (EC COM 2010/245), which was mainly formulated by the DG Information Society and Media (DG INFSO, now DG for Communications Networks, Content and Technology/CONNECT). It is the central strategy for all activities in the field of Information and Communication Technologies (ICT), which also includes CC and SNS. It is aimed at a "single digital market based on fast and ultrafast internet and interoperable applications exploiting the transformative power of ICT for smart, sustainable and inclusive growth".

It identifies seven challenges hindering this and suggests addressing them through eight corresponding pillars or action areas. These are:

- Digital Single market;

- $\quad$ Standards and Interoperability;

- $\quad$ Trust and Security;

- Very fast internet;

- $\quad$ Research and Innovation;

- $\quad$ Enhancing eSkills;

- $\quad$ ICT for societal challenges;

- International.

Each of the action areas is subdivided into a number of detailed specific actions, in total 101. Most of these actions are cross cutting actions, which are not directed at specific applications. Nevertheless, some of them will have direct consequences for CC or Social networks.

One example is the update of the e-Commerce directive (Action 9/Pillar Digital Single market). In the ground lying communication (EC COM 2011/942) five main obstacles for the Digital Single market and the Commission wants to address it in five corresponding priorities tackled with in total 16 main actions. It includes a framework for legal certainty in all electronic commerce activities including CC, the clarification of the VAT system, which is also crucial for CC in Europe, as well as new initiatives towards information and consumer protection. Within this it refers also to another major activity under the coordination of DG JUSTICE, the revision of the Data Protection Directive. Recently a new draft (EC COM 2012/09) was published that is aimed at more harmonised data protection regime in Europe. While it is welcomed by business, many national data protections authorities are more critically towards it. However it also refers to CC as well as SNS as main challenges for the new regulation of data protection in Europe. 
However other planned actions that have significance, but exclusively for CC and SNS are very fast Internet, Interoperability and Standards as well as Research and Innovation.

Above this overall strategy laid down in the DAE there is one specific thematic action ongoing regarding $\mathrm{CC}$, the so-called European Cloud Computing Strategy. ${ }^{1}$ It was initiated by a speech of NeelieKroes in January 2011 (Kroes SPEECH/11/50). It takes up the results of several earlier initiatives, in particular of the expert group on the future of Cloud Computing and the European Software Strategy, which both published their result in 2010. The process of a formulation of such a strategy encompassed several actions lines. Beyond an internal coordination between the different concerned DGs like DG JUSTICE, DG MARKET and DG ENTR under the heading of DG INFSO a public online consultation was launched in May 2011. Additionally several hearings with stakeholder groups, mostly business oriented, took place. Other activities are the coordination with US authorities in the filed of standards and Interoperability ${ }^{2}$. Above that the expert group on the future of Cloud Computing was re-established in 2012. Finally the topic is also a dedicated part of the Digital Assembly process on EU and national level.

Until now the main Unit of DG INFSO in charge was D3 Software and Services supported by other Units for specific aspects like F3/Geante e-Infrastructures for Scientific Clouds and standards. However with recent re-organisation of DG INFSO into DG CONNECT this may change again.

Nevertheless first results are already available. The results of the public online consultation were published by the end of $2011^{3}$ showing needs of clarifications in the legal framework, in particular regarding enforcement of contracts, consumer and data protection. Additionally the need for more research and innovation was stressed, but also the need for international cooperation since CC is a global phenomena. Finally the role of the public sector as adaptor of CC was highlighted. The different hearings as well as the industry recommendations stress similar topics. As a first consequence Commissioner Kroes announced in January 2012 a European Cloud Partnership aimed at developing common procurement requirements for Cloud services in the public sector (Kroes SPEECH/12/38). The idea behind is that the public sector with its significant market share of round about $20 \%$ is able to set standards regarding contracts, security etc. of which other market players in particular SME could benefit. The project funded with 10 Mio. $€$ will deliver such requirements and first implementations by the end of 2013.

\subsubsection{Activities on the EU Member State level}

Beside the activities on the EU level several member states also started activities, in particular in support of CC. In contrast, SNS are no specific topic of activities beside the ongoing discussion of data protection issues, only in a few cases they play a role in the discussion of citizens participation, which did not led to further initiatives on the policy level. Several countries like Finland or Germany launched technology research programmes

\footnotetext{
${ }^{1}$ See http://ec.europa.eu/information_society/activities/cloudcomputing/index_en.htm ${ }^{2}$ Related documents can be found here: http://ec.europa.eu/information_society/activities/cloudcomputing/library/index_en.htm ${ }^{3}$ http://ec.europa.eu/information_society/activities/cloudcomputing/docs/ccconsultationfinalreport. pdf
} 
as another pillar besides the R\&D funding for companies and research organisations by the FP7 programme. Another approach which is pursued by Great Britainwas the so-called "G Cloud" server as a national cloud for public services. Finally France combined both in the recently announced "Andromedé" project. However many other EU countries are in the progress of discussing or adopting strategies and programs.

The Finish program called "Cloud Software Program" is funded by the national funding agency Tekes and consists of a consortium of nearly thirty companies and research organisations. It mainly addresses software and IT service companies, which should be enabled to generate breakthroughs in the field of cloud technologies, Lean enterprises and business models, integrating user experience and security as value-adding elements. ${ }^{4}$ The German "Trusted Cloud" program, which is funded by the Federal Ministry of Economics and Technology, is clearly aimed at developing applications for the use in public services or private companies, in particular in small and medium sized enterprises (SME). Consequently the program is organised in four pillars: basis technologies, industrial applications, applications for the health system and applications for the public sector. It will be complemented in 2012 by another technology developing program called "internet based services for business", which will be a follow-up of the "Theseus" program. Together they form the main part of the action program "Cloud Computing", which deals additionally with international cooperation, knowledge transfer and creation of favourable framework conditions. $^{5}$

While these are mostly R\&D programs, the British "G-Cloud" is a so-called national cloud serving as a platform for all public services in Great Britain. The major aim is to reduce costs of public services through centralisation of infrastructures and the reuse of programs and apps. However the program steered by the Home office and the Ministry of Justice is the central pillar of the government's Cloud Computing Strategy and supports the overall ICT strategy for Great Britain by inter alia setting standards, creating lead users in order to enable the British ICT industry and supporting the take up of Cloud services in private business. ${ }^{6}$

Finally France announced and implemented the "Andromedé" Cloud, which is a combination of a R\&D support program and a national Cloud platform for public services as well as private business. It is funded with nearly 300 Mio. $€$ and led by a consortium of mostly semi-private companies like Thales. Since there were some troubles the project only recently started to get a clearerprofile. ${ }^{7}$

\subsubsection{I nternational activities}

Outside of Europe many countries also pursue different kinds of programs and strategies to deal with the challenges and prospects of CC. Most notably is the US "Federal Cloud Computing Strategy". Although it was only adopted in February 2011, it is based on a long-

\footnotetext{
${ }^{4}$ For more information see http://www.cloudsoftwareprogram.org/rs/2226/6e620c3b-438c-425c-bfcca70731023c59/8b3/fd/1/filename/cloudbroch-aug2011-net.pdf

${ }^{5}$ See http://www.trusted-cloud.de/documents/01_Goerdeler_BMWi.pdf

${ }^{6}$ See http://www.cabinetoffice.gov.uk/sites/default/files/resources/government-cloud-strategy_0.pdf

${ }^{7}$ See http://www.zdnet.fr/actualites/cloud-andromede-un-projet-sinon-rien-pour-dassault-systemes39770291.htm
} 
term process that started already in 2008 when the National Institute of Standards and Technology (NIST) started a process to define CC. As already mentioned many other countries refer to this definition and support the efforts of NIST for an international collaboration on standards regarding CC. The federal strategy outlines that CC is not only a paradigm shift for the IT industry, but that it changes the way how public services will work for citizens in terms of possibilities, and also in terms of efficiency and costs. As a consequencea Cloud First policy is introduced that requires that federal public administrations will take up Cloud services into their strategies. Above that the document also describes the necessary framework conditions for the public use and ways to achieve it. $^{8}$ In a first step NIST proposed a strategic roadmap dealing in detail with the requirements and challenges of $\mathrm{CC}$, in particular standardisation, data protection and security issues. ${ }^{9}$ Due to the prominent role of NIST this will also build a major input for the international collaboration efforts in these topics.

In Japan the Ministry of Internal Affairs and Communication (MIC) launched in 2009 the Digital Japan Creation Project (ICT Hatoyama Plan). It is aimed in general at creating new markets in ICT to support the Japanese ICT industry, but also Japans economy as a whole. One main pillar of this strategy is the establishment of a national Cloud for public services, called Kasumigaseki cloud. ${ }^{10}$ It is aimed at reducing costs of public services and burdens in particular for companies dealing with public services. This approach became gradually widened by a Smart Cloud Strategy adopted in 2010. It consists of three actions lines combining a national cloud platform and R\&D funding: 1) utilisation strategy (including Kasumigaseki Cloud), 2) technology strategy, and 3) international strategy. Whilethe public Cloud Kasumigaseki as well as a Cloud Consortium are already established, other points like technology development projects and standardisation efforts are still in progress. ${ }^{11}$ On the international level it not only collaborates with the US, but also strongly with South Korea and China. In South Korea the government also pursues a national Cloud Strategy aimed at exploiting the advantages for the public sector as well as for the private sector. Due to the low adaption rate it sees in particular the potential of the public sector as first mover to create standards and increase trust in it. ${ }^{12}$ However it seems that these are still ambitious plans for the future. In China Cloud development is still very limited. As a first step towards a national strategy in cloud development the government foresees the establishment of five Cloud Computing hubs in five selected cities. ${ }^{13}$

Summarising we can state that in particular in the field of CC many activities are on-going worldwide, which underlines the fact that it will be an international challenge.

\footnotetext{
${ }^{8}$ See http://www.cio.gov/documents/Federal-Cloud-COmputing-Strategy.pdf

${ }^{9}$ See http://www.nist.gov/itl/cloud/index.cfm

${ }^{10}$ See http://unpan1.un.org/intradoc/groups/public/documents/unpan/unpan037469.pdf

${ }^{11}$ See http://collaborate.nist.gov/twiki-cloud-

computing/pub/CloudComputing/ForumIVAgenda/111102_Kazutaka_NAKAMIZO_-

Panel_on_Cloud_without_borders1.pptx

${ }^{12}$ See http://collaborate.nist.gov/twiki-cloud-

computing/pub/CloudComputing/ForumIVAgenda/Panel_PresentationNIST_Workshop_111102_last_v 1.1.pdf

${ }^{13}$ See http://www.asiacloud.org/docs/Cloud_Readiness_White_Paper_v6-0.pdf
} 


\section{MAJ OR RESEARCH PERSPECTI VES}

Within the discourse on CC and SNS, there is a wide range of issues to be discussed and further analysed. During the consultation phase for this project, the participating researchers identified four areas which need to be worked out in detail: (1) Foundations of Cloud Computing, (2) impacts of Cloud Computing, (3) Social network Sites, (4) Enterprise Social Software. The following sections describe these issues and research perspectives in more detail.

\subsection{Foundations of Cloud Computing}

\subsubsection{Evolution of Cloud Computing concepts and technologies}

The idea behind CC can be traced back as far as the 1960s when the idea of a "computer utility" was developed (McCarthy 1961). "Computer utilities" were information services run from giant time-sharing mainframes. For an hourly fee one could sit down at a terminal in a local computer centre, and maybe - in the long run - even at home. In the late 1960s, practically everybody in academia and industry saw these as the unstoppable wave of the future. However, it became clear as the computer industry grew that no such consolidation of computing resources would occur as timesharing systems (Campbell-Kelly/Aspray 1996, pp. 215-19).

The idea had a revival with the birth and spread of the Internet in the late 1990, now called Application Service Providing (ASP). Application service providers offered access to a particular application program (such as customer relationship management) using a standard protocol such as HTTP. The ASP model was related to the growing trend in industry to outsource specific computer applications so that they could concentrate on their core competencies. Like the "computer utility" ASP was only a short-lived trend that did not meet the great expectation raised by industry. The reason this failure was mainly that the performance of computer networks was still to low for real-time operation of complex interactive software (Friedewald et al. 2001).

The launch of Amazon Web Services in 2002, providing services like storage, computation and even human intelligence, can be regarded as the start of CC as we understand it today. What was initially meant as a way to market surplus capacities of Amazon's data centres became a proper product in 2006, when Amazon started the Elastic Compute Cloud as a truly commercial service open to everybody. In subsequent years all the big players became active in the CC and when Microsoft, Oracle and Hewlett-Packard launched their services in 2009, CC has become mainstream.

Since CC is really crosscutting, all areas of computer science and engineering are contributing to the technological basis, often triggered by new business models developed by the powerful incumbents but even more often by creative new application ideas of startup companies, such as "Dropbox". 
These technological developments have been published in the journals, transactions and conference proceedings of the international professional associations, in this case mainly the "Association of Computing Machinery" (ACM) and the "Institute for Electrical and Electronics Engineers" (IEEE). We will depict the evolution of concepts and technologies in the basis of an intensive literature search in the repository of both organisations complemented by a search in the growing number of specialist media such as the "International Journal of Cloud Computing" or the "International Journal of Cloud Applications and Computing". We will concentrate on articles giving and overview of the development and/or state-of-the-art of the technology development and on technology foresight oriented articles that outline likely and possible future developments.

\subsubsection{Challenges and opportunities to Cloud Computing in Europe}

Due to the fact that CC is a hype topic the number of publications related to it is huge. However regarding challenges and opportunities we can differentiate between two different sets. On the one hand the literature on how CC is adopted (or not) by users, which reflects the demand side, and on the other hand the literature on why there are no internationally successful European Cloud Computing providers, reflecting the supply side. Both topics are interrelated and as a consequence we will address them both in our study. Moreover both topics have two dimensions: the micro dimension, i.e. user or firm level, and the macro level, i.e. legal, cultural and political framework, which are also strongly interrelated. One example in the field of adaption are the concerns of users, indifferent if they are private persons or private companies, regarding the security of their data that is strongly related to the questions of the regulatory framework for data protection, but also to cultural dimensions like general trust. However we will try to give an overview on the state-of-theart research on both and finally derive short conclusions, in particular regarding the design of the research on these topics in the project.

The lagging behind of Europe in the IT sector is a phenomenon that is researched in regular intervals since the 1970s. While in the time until the 1990s the IT hardware industry built the main focus, the interest has then shifted towards Software, IT services and Internet. However nothing has really changed since this time. Today 14 of the world's Top 20 software vendors are US-based, which account for more than $37 \%$ of the worldwide market, while there are only 3 European companies, with only $5 \%$ of the market (Aumasson et al. 2010). This description was part of one of the last studies dealing with the European Software and Services industry, which is also confirmed by other studies showing that the competitiveness situation of the software and IT services industry in most EU member states is lagging behind the US (Leimbach/Wydra 2010). The study was part of the already mentioned development of a European Software Strategy, the predecessor of the current Cloud Strategy. It mainly focussed on the development of the market for Cloud and Mobile Software and Services and barriers for it and was based on stakeholder interviews and two workshops with stakeholders, policy-makers, and academic people. The results were not surprisingly that the lack of a single market, the lack of harmonisation in the regulatory environment like data protection or VAT rules as well as a lack of sufficient financing opportunities and skilled workers is still the biggest obstacles for European countries. Nevertheless the study also identified many measures, but one result is that a 
lack of coordination in these policies like coordination of R\&D funding and pre-commercial procurement is also one of the challenges for a successful policies. Many of these results were confirmed by other studies, which mainly deal with subgroups of the industry. Examples are a study on the competitiveness of ICT SMEs in Europe (Ecorys 2009) or the research on fast growing enterprises called Gazelles or Yollies (Young Leading Innovators), which uses the IT industry besides other high-tech and knowledge intensive industries as one prominent example (e.g.Veugelers/Cincera 2010, Veugelers/Schneider 2008). The first one shows clearly that small and medium enterprises suffer of the same problems as the rest of the industry. Some of the obstacles like the shortage of skilled employees are even worse for them due to the fact that many graduates think they are less attractive employers (Ecorys 2009). This result is no surprise given the fact that most of the European software and IT services industry consist of SME. The latter type of studies focuses on fast growing companies in different stages of development. Although their share in the total number of enterprises is quite low, analyses show that they have a disproportionate share in economic growth (Veugelers/Cincera 2010). Examples from the US for this phenomenon are very often companies of software and Internet industry like Microsoft, Google or Facebook. In their conclusions these studies focus strongly on structural deficits in the EU innovation policies, in particular the R\&D funding systems and the financing of growth (Veugelers/Cincera 2010, Lilischkis 2011, Phillipon/Veyron 2008). However the results of these studies are not surprising, but although the problems are well known policy has not managed to overcome them until now. Many of the previous initiatives like on the digital single market mitigated some barriers, but were not sufficient in removing them and creating a true single market.

While these studies mostly focus on the barriers for the growth and competitiveness of companies and the industry itself in Europe, many other studies focus on the demand side, in particular in the case of CC. Most of these studies are carried out by market researchers and consultants and are based on surveys with different types of customers, i.e. private consumers, public institutions or private business. Often they try to explain why CC is adopted or not and what are the reasons for this behaviour. By analysing these reports three points become obvious: Firstly the quality of studies varies strongly, because the number of participants is often rather low. Secondly in some cases it is obvious that they are influenced by the interests of the market researchers and consultants who run the studies. Thirdly and finally, many of the studies are limited in the depth of their analysis. Mostly they only describe driving forces and barriers, but they do not analyse them. Most important insight of the ones that have an international comparative character is that the often-used thesis that in particular Europe is lagging behind in the adoption of Cloud Computing Services seems to be true (e.g. TCS 2012). Some of the studies even reach the point to name several things like data protection, regulatory framework or similar as reasons (e.g. Gartner 2011), but they lack of analysis and policy perspective on these topics for further research. However there are two studies recently finished or in progress that are aimed at this. The first one was published in the beginning of this year as a report to the European Parliament's Committee on Internal Market and Consumer Protection (Fiedler et al. 2012). It identifies lack of privacy, data security, provider lock-in, lack of standardisation, and jurisdictional issues relating to applicable law and law enforcement access to data as main perceived barriers based on the report of ENISA on concerns of SME 
towards CC in Europe and the related risk assessment (ENISA 2009a, ENISA 2009b). Additionally the study also examines obstacles to digital single market, mainly based on the material of the EC Cloud Strategy process and finally tries to sketch a possible future of CC. In opposite to this the second study, which was commissioned by the former DG INFSO as part of the Cloud Strategy process, encompasses a European-wide survey and analysis of market potential as well as driving forces and barriers for CC. Until now only an interim report is published that gives an outline of the first results of the survey (Cattaneo et al. 2012). Nevertheless these intermediary results show some interesting findings. On the one hand not only cost reductions, but also other factors like integration of processes or mobility are main drivers and benefits for the participants. Regarding barriers it identifies three main clusters of problems: 1 ) trust, security and data protection; 2) data location and jurisdiction; and 3) interoperability and portability. Not surprisingly these results confirm the research of others like ENISA (2009a). Finally it also shows the participants priorities regarding the question what is needed to increase the adaption, but since it is only an interim report there are no further analyses at this stage.

Summarising we can state that there are many studies regarding the two points addressed in this part. Some of them could be used as a basis for a further research and analysis, but due to the two different viewpoints this analysis requires an integrative approach to combine the demand and suppliers perspectives. Therefore a systemic view is necessary to analyse and understand the interrelations between both. This is a necessary requisite for further analyses of benefits and risks and most important also for conclusions and recommendations on a policy level.

\subsection{I mpacts of Cloud Computing}

\subsubsection{Economic and social impacts of Cloud Computing}

Although CC is often regarded as a future technology, evidently the "cloud is here already" (Sultan 2010). But some factors hinder a realistic assessment of its current and future impact on economy and society. Firstly, what exactly is considered as CC varies with the multiple different (and sometimes unclear) definitions used, which is especially problematic when it comes to large-scale economic estimations and comparisons. Secondly, the ongoing hype about this technology blurs the picture even more. High expectations have been placed on it, since it apparently comes with a promise: "The promise of cloud computing is to deliver all the functionality of existing information technology services (and in fact enable new functionalities that are hitherto infeasible) even as it dramatically reduces the upfront costs of computing that deter many organizations from deploying many cuttingedge IT services"(Marston et al. 2011).

Remarkably, many studies which stress the positive potential of CC come from a technology or marketing perspective, whereas the "literature directly on topic written by economists is extremely small" (Bayrak et al. 2011, p. 214). By contrast, a number of commercial market and technology research institutes have conducted studies on the economic potential of CC. Mostly, they focus less on the current market situation and more 
on the expected impact in the future in which CC is widely believed to play a major role. For example, a highly cited report by Gartner Inc. (2010) predicts that the worldwide cloud services revenue will reach 148.8 billion USD by 2014. Since Gartner operates with a rather broad definition of $\mathrm{CC}$, it has been argued that these estimations are probably too high (Bayrak et al. 2011). According to the Gartner report, the global CC market of 58.6 billion USD in 2009 was US-dominated with a market share of $60 \%$ which was expected to decline in favour of a larger international market share, especially in Western Europe which was believed to reach $29 \%$ by 2014 .

A recent study by the International Data Corporation (IDC) estimated that the 2011 EU public cloud business market for software services was 3.5 billion Euros and 1.1 billion Euros for hardware services ${ }^{14}$ (Cattaneo et al. 2012). In relation to the EU IT market that time, this is still a rather small segment of around $1.6 \%$ (Cattaneo et al. 2012).

Nevertheless, CC has broader implications for other fields. It was regarded as a key technology that might help to overcome the dominance of US companies in the software market, since the "delivery models of application software products are dramatically changing with the advent of the cloud computing and SaaS models" (Aumasson et al. 2010, p. 34). However, Aumasson et al. also stress the still existing clear dominance of US companies (see 2.1.2 for a further discussion on this).

Especially SMEs are believed to benefit from CC because it enables them to utilize computation capacity on-demand, while outsourcing its maintenance. Although this may also be an advantage for larger corporations, it is particularly attractive for those SMEs which are not able to keep a sophisticated hard- and software infrastructure on a reasonable basis. Parallels Inc. calculated that the global CC market for SMEs was around 34 billion USD in 2011 and estimated it will grow up to 68 billion USD by 2014 (Parallels Inc. 2012). Operating with a rather broad understanding of CC (including e.g. simple web hosting) and being itself a CC provider, this number is likely to be inflated. Still, it is not the only optimistic outlook with this perspective. Although the reduction of costs will correlate with job loss (since outsourcing will replace parts of the IT staff), some argue that the new business opportunities for SMEs etc. create new jobs, possibly outnumbering job losses. For example, Etro estimated that $\mathrm{CC}$ will be "contributing to create about a million new jobs through the development of a few hundred thousand new SMEs in the whole EU-27" (2009, p. 180) within five years by the time of the study. A report analysing the economic impact of CC in France, Germany, Italy, Spain and the UK concludes that, for those customers, the "widespread adoption of cloud computing has the potential to generate over $€ 763$ billion of cumulative economic benefits over the period 2010 to 2015" (CEBR 2010, p. 7). As Etro, the study foresees a massive and even larger job growth triggered by CC: "We also find that widespread cloud computing adoption has the potential to support significant direct and indirect job creation which, across the five economies, we predict to be in excess of 2.3

\footnotetext{
14 This terminology is further described as follows: "Public cloud software covers AaaS (Applications as a Service), PaaS (Platform as a service or Application Development and Deployment as a service), and IaaS SW (Infrastructure software as a service). Public cloud hardware covers Cloud servers and Cloud storage (disk systems)" (Catteneo et al. 2012, p. 66).
} 
million net new jobs on a cumulative basis over the period 2010 to 2015." (CEBR 2010, p. 7)

While both studies share an optimistic outlook, their estimations vary significantly. Given the many factors involved in such calculations, this is not surprising. Still, despite of discrepancies in certain details ${ }^{15}, \mathrm{CC}$ is widely regarded as a job engine with a positive impact on growth. But there is also no doubt that CC has become a major hype as a number of authors have noticed (e.g. Vaquero et al. 2008; Erdogmus 2009). Indeed, there are many obstacles which hinder CC to fully unfold, especially security issues, privacy concerns and a partly unclear legal situation (see 2.1.2, 2.2.2).

Apart from effects on revenues and employment, CC has an impact on further areas of society. Firstly, the advent of Web 2.0 has created countless popular platforms for consumers for various everyday life situations: file hosting services (e.g. Dropbox), image hosters (e.g. Flickr), video hosters (e.g. YouTube), location-based services (e.g. navigation software) and many more. Our project will focus more closely on the prominent example of social network sites (see 3.3) and enterprise social software (3.4).

A large effect of CC can be seen in science. In particular, data-intensive scientific fields have started to apply CC (see e.g. Praveena/Betsy 2009). Again, the main argument in favour for $\mathrm{CC}$ in this context is its potential to reduce costs and giving novel opportunities for researchers. Typical CC features such as scalability and the possibility to create easy-touse platforms are obviously practical for scientific purposes and advantages of CC in educational settings have also been pointed out (Ercan 2010). Moreover, academia itself has initiated some CC projects such as OpenNebula (funded by FP7/2007-2013), which is open source and gets applied in a number of scientific projects, e.g. at CERN. While there is certainly demand and benefit of CC in data-intensive "big science", critics have also warned about unintended side effects. Also academia has to face the general CC problems like security and other technological issues (see e.g. Hoffa et al. 2008) and the legal situation and its consequences are partly unclear (Vaidhyanathan 2011). Additionally, methodological concerns have been expressed and the trend of shifting university resources from "lab space [...] toward server space" (ibid., p. 197) has been criticized.

Another social effect of CC can be seen in new forms of participation for civil society actors such as NGOs, journalists or individuals who benefit from the lower access hurdles to computing resources. There are already cloud solutions specifically for the target group of non-profit organizations (e.g. The Humanitarian Cloud) and NGOs have initiated their own CC projects like The NetHope Humanitarian Cloud Services Portal (Brindley 2012). This may not only help to reduce IT costs but also to ease information flows (possibly in combination with applications for mobile devices). This aspect is particularly interesting for journalists, too. While the Internet is widely regarded as a threat for professional journalism, CC technology has fostered the new field of data-driven journalism. Cohen et al. have stressed the potential of CC in this context by suggesting "a cloud for the crowd, which combines

\footnotetext{
${ }^{15}$ For example, Cattaneo et al. (2012) expect that large companies will play a more important role in the European CC market, on the customer side, than SMEs. Moreover, apart from the quoted studies with a broader perspective, a number of studies focus more closely on specific realms such as regions (e.g. Kobyliński/Michalski 2011) or certain sectors (e.g. Liebenau et al. 2012), which we cannot discuss in detail at this stage.
} 
computational resources as well as human expertise to support more efficient and effective investigative journalism" (2011, p. 148). With services like DocumentCloud.org, allowing for analysing and publishing primary source documents, this is already reality. The case of WikiLeaks is another prominent example in this context. On the one hand, its whistleblowing activities were embraced as a form of democratization, on the other hand they were criticized as a threat. At the same time, legal issues became apparent when Amazon removed WikiLeaks from its cloud services (Kushida et al. 2011).

Another potential impact is that CC might be misused for clearly criminal activities, in particular, by paedophiles. Therefore, it was suggested that law enforcement should monitor CC content, fearing that otherwise "the number of crimes that will go unpunished will be great" (Biggs/Vidalis 2009, p. 5).

This brief overview shows that $\mathrm{CC}$ has a potentially massive impact on economy and society, with a number of opportunities but also risks associated to it. These have to be studied carefully to provide a realistic assessment of the complex effects triggered by this technology. This will also require a more differentiated analysis and comparison of the studies at hand.

\subsubsection{Security, privacy, intellectual property/ copyright and other legal issues of cloud computing}

The bulk of the literature on cloud security addresses responsible use of cloud computing services and how to protect oneself from the inherent risks in cloud services. Assessments relating these challenges to policy are few to this date.

A main debate arising from the extensive use of cloud computing is one of security, i.e. whether cloud infrastructures are indeed able to meet and maintain the levels of confidentiality, data protection and reliability traditionally associated with a sensible ICT infrastructure. This debate relates to fundamental issues of accountability in multistakeholder service agreements as well as to questions about the right to privacy and its application in cloud computing.

Openness of operators towards end-users regarding security safeguards does seem to be the key to further developments in cloud computing as accountability and trust become still more crucial issues. With a society-wide shift towards cloud computing underway a new security paradigm emerges in which the providers' right to secrecy becomes a hindrance to clients' internal security requirements.

\section{Security}

Potential security problems include

- Confidentiality: Users might store sensitive data on remote computers. Insiders or hackers could gain access (Falliere et al. 2011, Ristenpart et al. 2009, Cachin/Schunter 2011).

- Integrity: Providers might modify data (Cachin/Schunter 2011, Cabuk et al. 2010).

Availability: Data might be lost or not available (Infoworld 2011, Enisa 2009c).

In more detail, the security issues at stake (listed in ENISA 2009d) are: 
- Loss of governance, i.e. transfer of security maintenance to the service provider.

- $\quad$ Lock-in, due to the lack of standard means for transporting accounts between clouds.

- I solation failure, i.e. the danger of other cloud users gaining unintended access to data.

- Compliance risks, i.e. the risk that use of cloud services may void compliance with industry security standards or regulatory requirements.

- Management interface compromise, i.e. the inherent security compromise that lies in setting up an internet-based interface as the main access point to one's data, which in principle makes it accessible to hackers.

- Data protection (assurance), issues regarding data handling practices and the inability of customers to check for themselves the practices of service providers.

I nsecure/ I ncomplete data deletion, i.e. the risk of data being deleted but not entirely wiped and thus remaining accessible in principle.

- $\quad$ Malicious insider, i.e. risks arising from industrial espionage or vandalism.

\section{Technical approaches}

- Confidentiality: Technologies might be designed to give providers no access to data. For example, approaches from Trusted Computing could be used (Cabuk et al. 2010) or homomorphic encryption (Gentry 2009). Computer security could be increased to reduce hacks (Grawrock 2006, Heiser 2010).

- Integrity: Data could be digitally signed (difficult if one wants to do computations on them).

Availability: Providers could use independent backup centres. Users could back up data and migrate to other providers. DDoS could be fought (difficult in practice).

Alternatively, legal approaches could be used, certification of providers, more redundancy be provided, etc.

\section{I mplementation of more security}

As the maintenance of hardware security and data protection now rests squarely on the cloud provider, clients need a level of insight into the business practices of the provider, which traditionally can only be obtained through audits. In the case of providers with thousand or even millions of clients, individual audits are not feasible as they have proved to be a great strain on providers. Several expert sources (e.g. ENISA 2009 and WEF 2011) therefore recommend the creation of a standard auditing regime, through which clients can gain easy access to the information they need.

From a societal point of view, however, the practice of auditing providers is inefficient, and does not generate an environment of general trust in cloud computing as infrastructure. The cloud computing industry, therefore, focuses its trust-creating efforts on standardization. (https://cloudsecurityalliance.org) Implementation of standardized procedures of security could limit the use of auditing to special-case users such as research intensive businesses, extra sensitive government branches, or military. And it would 
enhance trust in cloud providers, enabling smaller public administration units and SMEs to safely reap the benefits of cloud computing.

Together, the above-mentioned risks amount to a security threat of existential proportions to organizations. Data security failure can lead to serious reputation damage and even business failure, consequences which cannot be mitigated by any compensation by the cloud provider. Similarly for individuals, serious privacy transgressions can have irreversible impacts on a person's life. At its core, the risk issue is thus related directly to the ethics of data management.

\subsection{Social Network Sites}

Social Network Sites (SNS) offer novel communicative possibilities; above all they link-up its members and map their offline networks (e.g. Boyd/Ellison 2007). They are among the rapidly spreading services over the World Wide Web; the increasing diffusion of SNS and related services on a global scale is inter alia visible in diverse website rankings (such as from leading web metrics provider Alexa.com), where several SNS are present in top ranks, e.g. Facebook as second most popular website worldwide (right after Google), Youtube (3rd), Twitter (8th), LinkedIn (12th) ${ }^{16}$. Though such rankings are soft indicators they refer to the growing importance and societal impact of SNS for different forms of online activities. SNS provide a variety of low-threshold ways to establish, modulate and extent different network-based relations. Usage contexts of SNS range from private purposes (e.g. dating, seeking friends) to professional networking (e.g. job seeking, education, business contacts, science and research). SNS are the most prominent example for new modes of interaction in digital environments and demonstrate the effects of many-to-many relations: SNS are not only means for single users to interact with others based on common interests but also provide various options for user groups, organizations or institutions to present themselves to a wider public and extent their contacts (e.g. communities, grassroots, public institutions). These new modes of interaction entail a variety of new possibilities to share and create content.

As the term implies, networking and interactions among users within a specific virtual environment is a core feature of SNS. Though SNS are a recent phenomenon, already classical studies about social interactions and networking such as Milgram's exploration of the "small world problem" (Milgram 1967), stating that every person knows every other person worldwide over six degrees of contacts provide valuable insights into the modes of user interactions. More recent studies examined the "small world" hypothesis in the context of Internet communication; e.g. (Leskovec/Horvitz 2008) analysed 240 Mio. Instantmessenger accounts in this regard and come to similar results whereas every user knows every other user over approx. 6,6 knots. A further characteristic of SNS is related to (Granovetter 1973) theory of "the strength of weak ties", stating that contacts that are loosely bound to other contacts are expected to have a wider network and thus might also benefit from extended access to information (Heidemann 2010). SNS are thus seen as

\footnotetext{
${ }^{16}$ See http://www.alexa.com/topsites, May 212012.
} 
valuable tools to support distance learning, community building and stimulating the development of social capital (e.g. Hoffman 2009; Wimmer 2009; Heidemann 2010).

While these characteristics are similar in different sorts of SNS, they differ according to the particular SNS type and related user groups. SNS that aim at special user groups with a sort of pre-defined professional scope (e.g. ResearchGate, aiming at researchers, LinkedIn or Xing for business contacts etc.) provide a more explicit option for personal reputation management and networking in a professional sense. Opposed to those, general SNS like Facebook or Google+ seem to have less focus on specific target groups and aim at maximizing the amount of users. These different foci can be expected to have certain impact on the ways users interact with the SNS and their perceptions and expectations of usage.

Despite of the manifold different usage contexts, sharing personal data and information play an essential role in the very design of SNS as every form of social interaction needs a certain amount of information about the parties involved. On the one hand, the wide range of new possibilities for content-sharing and creating supports community building and collective actions; on the other, it further stresses informational privacy and the users controllability over his/her personal information in several ways (and not least due to complex modes of data processing that refer to distributed computing in the cloud). Or in other words: the distinction between personal information and user content diminishes further within social networks.

Thus, privacy, trust and proper handling of personal information are crucial aspects of SNS. In this regard there are potential conflicts between users' intentions to share personal information and the way these information is used by the SNS (e.g. behavioural targeting and processing of user data for commercial interests). These issues are not least affected by the interplay between privacy awareness, different usage patterns and features supported by the SNS.

The usage and impact of SNS has already been explored in various studies, covering sociological aspects (e.g. Ellison et al. 2007; Wanhoff 2011; Röll 2010; Steinfield et al. 2008), psychological issues such as Internet addiction (e.g. Valkenburg et al. 2006; Livingstone 2008) and commercial aspects, such as the business models of SNS and related companies, including data mining for marketing and other purposes (e.g. Elmer 2004; Häusler 2007; Fraser/Dutta 2008) as well as academic usage (e.g. Nentwich/König 2012). Some of the studies focus on usage and non-usage as well as usage patterns in particular (e.g. Hargittai 2007), often times with a particular focus on young users (e.g. Amanda/Mary 2007). Many studies on SNS focus on privacy and trust (e.g. Fuchs 2009; Fuchs 2010; Gross/Acquisti 2005; Biermann 2010; Ferdig et al. 2008; Lehavot 2009; Lewis et al. 2008; Barnes 2006; Cain et al. 2009; Lack et al. 2009; Dwyer et al. 2007). Further hot issues are the potential misuse of SNS (including risks for child safety, emotional abuse, online bullying etc.)(e.g. Boyd 2007). Opposed to those critical aspects, there is a variety of positive effects such as stimulating social learning, enabling new modes of participation, strengthening community building and empowerment (e.g. Wimmer 2009; Pratchett et al. 2009). 


\subsection{Enterprise Social Software}

The first success of SNS in the mid of 2000s led to many discussions how companies could use elements of social network to improve their work. These discussions were not only limited to the question on the use of using it in the communication with customers, but also to improve the communication and work within the company itself. In his ground laying article "Enterprise 2.0: The Dawn of Emergent Collaboration", Andrew McAfee (2006) took this up and tried an initial description of elements, but foremost he shaped the term of Enterprise 2.0 (E2). Afterwards this idea and especially the term E2 was picked up by professionals, consultants, academics and politicians to explain the possibilities for enterprises using the new technologies in their daily business. But as happens so often, it is not clearly defined what E2 actually is and what it requires or contains (technical, organizational, etc.). McAfee himself described the characteristics of E2 with the word SLATES (search, links, authoring, tags, extensions, signals).

This refers to the basic functionality of a set of Web 2.0 or Social Software:

- $\quad$ To enable the location of information (searching)

- $\quad$ To enable user to easily connect information (linking)

- $\quad$ To allow user to provide and create own information (authoring)

- $\quad$ To enable user to structure data (tagging)

- $\quad$ To enable the build-up of modular, service-oriented applications (extending)

- $\quad$ To inform users easily about new contents (signalising).

Another possibility to characterise E2 is to sum up all the social software tools that fulfil these functionalities like Wiki, Blog, Social Tagging, Social bookmarking, Group Editors, Instant Messaging or other collaborative tools. Other characterisations, for example by functionalities, are also possible. Therefore one challenge at the moment is to develop a convenient characterisation and definition that does not only take technological developments into account, but that also reflects other developments like organizational changes, i.e. new internal and external organizational forms like outsourcing, networking, mobile/flexible offices, as well as market development like globalisation, knowledge intensity or enforced innovation dynamics.

While the first uses were often initiated by individuals and small teams that started using blogs etc. for their work, the following years were coined by the fact that companies explicitly tried to establish tools. These were mostly aimed at communication and collaboration (project management) and knowledge creation and sharing (knowledge management) (Osimo et al. 2010). These efforts were often based on using existing tools like the open source software for blogging(such asWordPress) or Wiki software (such asDokuWiki). Moreover forerunners like the British telecom went beyond that developing application bundles or suites tailored to their own needs. Consequently many providers for business software like IBM or SAP also started to take up this idea and introduced social networking in their portfolio. Consequently most of these solutions were on-premise installation, e.g. they were part of the IT system of the enterprise. However many 
companies, in particular small and medium sized enterprises, were not able to develop or buy such complex systems.

As a consequence some suppliers started to offer their social network services as a web based solution for enterprises. Most typically these services started with a limited set of functionality and later on developed into full-fledged services. A typical example is Yammer, which was one of the forerunners of these developments. It started in 2008 as a micro blogging service for enterprises. In opposite to the more well known Twitter, which is a public micro blogging service, Yammer was from the beginning focussed on enabling private communication within organisations or defined groups of persons. Other examples are present.ly, socialcast, and socialtext. Based on the success of this first application Yammer started gradually to expand the set of functions, mostly inspired by public SNS like Facebook. In 2010 a major relaunch took place and Yammer 2.0 was advertised as a "Facebook for enterprise" (Rao 2010). However there are clear differences between them. While in the case of Facebook the discussion whether it is a Cloud Computing Service or not is an open discussion (Fielder et al. 2012), the case of Yammer is much clearer. In opposite to Facebook or Twitter Yammer defines closed social network for each enterprise, where other enterprises or the public do not have access to. Above that companies are able to fully administrate their own social networks within Yammer, i.e. create or block users or functions. Finally it uses the same business models like other Cloud Services such asDropbox, i.e. a so called "freemium" approach where basic services are for free while more advanced uses require a premium account based on a fee per user. However in these cases Yammer requires contract not with individual employees, but with the enterprise as a whole, which is also a clear difference to other public SNS.

Due to this evolution the state-of-the-art of research varies strongly (Richter et al. 2011). In general, most of the literature on Enterprise 2.0 or Enterprise Social Media (e.g.Eberspächer/Holtel 2010, Richter 2010, Koch 2009, Back et al. 2008) is focussed on classical on-premises installations. Above that many publications are focussed on single functions coined by terms like Knowledge Management 2.0 (e.g. Levy 2009) or Project Management 2.0 (e.g. Levitt 2011). As a consequence this type of research is strongly focussed on the opportunities and challenges for successful implementation of such tools on the micro level, i.e. in the company itself. As a consequence topics like IP rights, data protection or similar play only a minor role as far as they are relevant within an enterprise. However many authors even do not consider these points. Moreover much of the literature is written by consultants or other non-academic people, who often give the literature a typical "how to implement" manner (e.g. DB Research 2010, IBM 2008). The macro level of regulatory and political implementations of the use of such tools in enterprises is even more limited. Beside the classical market studies there is only one project of the European Commission, which was carried out from 2009 to 2010 (Osimo et. al 2010). It strongly focuses on reasons why European providers of social software tools lagging behind providers, in particular the ones from the US. However the conclusions drawn like the lack of international players and the fragmentation of the market are similar to most other studies (see also section 2.1.2). The policy recommendations focus on innovation policy recommending other forms of funding for such industries as well as a stronger role of the public sector as first mover. 
All these research and literature do not deal explicitly with the new form of web-based enterprise social software and its implications in particular. However due to the fact that these offers are in principle a Cloud Computing Service with many features of SNS, our research will strongly rely on the state-of-the-art research in these distinctive fields (see sections 3.2 and 3.3). Additionally we will try to identify if there are specific challenges and barriers for the acceptance of such offers and the growth in Europe mainly by field research, i.e. telephone interviews with European providers like Communote and others as well as users of these services. 


\section{MAI N RESEARCH QUESTIONS}

In the previous sections of this interim report a number of important issues with regard to CCand SNS were raised and discussed in detail. The main objective of the desk research was to identify, sharpen and substantiate relevant perspectives and topics for the remaining phases of this STOA-project. Based on the insights gained, the project addresses the following research questions, which are presented in the following in three issue clusters:

- $\quad$ Potentials and impacts of Cloud Computing for Europe

- $\quad$ Risks and Benefits of Social Network Sites

- Policy Implications

The annex (project plan) of this interim report will clarify how these questions will be answered during the course of the project.

Potentials and impacts of Cloud Computing for Europe

- Which technological and economic developments are major pave makers for cloud computing?

- What are the driving factors and barriers for the further evolution of cloud computing in Europe? Who are the main actors and what are their interests?

- To what extent does cloud computing impact the European ICT industry, other industries, public administration, research and science as well as consumers? What are the impacts on society and economy as a whole?

- What are the security, privacy, intellectual property/copyright, and other legal issues related to cloud computing?

Risks and Benefits of Social Network Sites

- $\quad$ How did SNS evolved and occurred in a Europe?

- What are the major drivers and barriers of SNS to change and broaden social interactions?

- What are the main societal impacts of SNS usage (with respect to different types and usage contexts of SNS)?

- What are the relevant socio-technical issues and governance challenges related to SNS (such as privacy regulations and technical responses as regards privacy-bydesign, options for self-regulation)?

Policy Implications

Which actions are appropriate to exploit the potentials and benefits for the European society as a whole?

- Which actions are appropriate to reduce risks and negative impacts? 
- What are the options for action for European decision-makers and in particular for the European Parliament?

- What are the foreseeable needs for parliamentary activity? 


\section{REFERENCES}

Amanda, L. and Mary, M., 2007, Social networking websites and teens: an overview: Pew Internet and American Life Project.

Aumasson, A., Bonneau, V., Leimbach, T. and Gödel, M., 2010, Economic and Social Impact of Software \& Software-Based Services. Smart 2009/0041, Paris: Pierre Audoin Consultants SAS (PAC).

Back, A. et al., 2008, Web 2.0 in der Unternehmenspraxis, Oldenbourg.

Barnes, S. B., 2006, A privacy paradox: Social networking in the United States, First Monday 11(6).

Bayrak, E., Conley, J. P. and Wilkie, S., 2011, The Economics of Cloud Computing, The Korean Economic Review 27(2), 203-230.

Biermann, K., 2010, Facebook, bing und Skype vernetzen sich, Zeit Online, 15.10. <http://www.zeit.de/digital/internet/2010-10/facebook-bing-skype>.

Biggs, S. and Vidalis, S., 2009, Cloud computing: The impact on digital forensic investigations, International Conference for Internet Technology and Secured Transactions, ICITST, 9-12 November 2009, London.

Boyd, D. M. and Ellison, N. B., 2007, Social Network Sites: Definition, History, and Scholarship, Journal of computer-Mediated Communication 13(1), 11.

Boyd, D. M., 2007, Why Youth (Heart) Social Network Sites: The Role of Networked Publics in Teenage Social Life, in: Buckingham, D. (Ed.): MacArthur Foundation Series on Digital Learning - Youth, Identity, and Digital Media Volume, Cambridge, MA: MIT Press, 119-142.

Brindley, B., 2012, The Next Leapfrog for Development: Leveraging Cloud Computing, NetHub, May 25 <http://nethope.org/blog/2012/05/the-next-leapfrog-fordevelopment-leveraging-cloud-computing $>$.

Cabuk, S., Dalton, C.I., Eriksson, K., Kuhlmann, D., Ramasamy, H.V., Ramunno, G., Sadeghi, A.R., Schunter, M., Stüble, C., 2010, Towards automated security policy enforcement in multi-tenant virtual data centers. J. Comput. Secur. 18, 89-121.

Cain, J., Scott, D. R. and Akers, P., 2009, Pharmacy Students' Facebook Activity and Opinions Regarding Accountability and E-Professionalism, American Journal of Pharmaceutical Education 73(6), Article 104.

Campbell-Kelly, M and Aspray, W., 1996, Computer: A History of the Information Machine, New York: Basic Books.

Cattaneo, G., Kolding, M., Bradshaw, D. and Folco, G., 2012, Quantitative Estimates of the Demand for Cloud Computing in Europe and the Likely Barriers to Take-up. SMART 2011/0045, D2 - Interim Report: International Data Corporation.

CEBR, 2010, The Cloud Dividend: Part One. The economic benefits of cloud computing to business and the wider EMEA economy. France, Germany, Italy, Spain and the UK, London: Centre for Economics and Business Research.

Cachin, C., Schunter, M., 2011, A Cloud You Can Trust - How to ensure that cloud computing's problems-data breaches, leaks, service outages-don't obscure its virtues, IEEE Spectrum, December 2011, pp 28-51.

Cohen, S., Li, C., Yang, J. and Yu, C., 2011, Computational Journalism: A Call to Arms to Database Researchers, 5th Biennial Conference on Innovative Data Systems Research (CIDR '11) January 9-12, 2011, Asilomar (CA).

Coombes, R. and Siddiqi, J., 2008, A Framework for IT as a Utility, Fifth International Conference on Information Technology: New Generations.

Gentry, C., (2009) Fully Homomorphic Encryption Using Ideal Lattices. In the 41st ACM Symposium on Theory of Computing (STOC), 2009.

DB Research, 2010, Enterprise 2.0 - Wie Unternehmen das Web 2.0 für sich nutzen, Frankfurt/M.

Dwyer, C., Hiltz, S. and Passerini, K., 2007, Trust and Privacy Concern Within Social Networking Sites: A Comparison of Facebook and MySpace, in: Proceedings of the 
Thirteenth Americas Conference on Information Systems, Keystone, Colorado August 09 - 12 2007: Association for Information Systems.

Eberspächer, J. and Holtel, S., 2010, Enterprise 2.0. Unternehmen zwischen Hierarchie und Selbstorganisation, Heidelberg.

EC COM 2010/245, 2010, Digital Agenda for Europe, Brussels.

EC COM 2011/942, 2011, A coherent framework for building trust in the Digital Single Market for e-commerce and online services, Brussels.

EC COM 2012/09, 2012, Draft DTA protect Safeguarding Privacy in a Connected World A European Data Protection Framework for the 21st Century, Brussels.

Ecorys et al., 2009, Competitiveness of the EU SMEs in the ICT services industry, Rotterdam.

Ellison, N. B., Steinfield, C. and Lampe, C., 2007, The Benefits of Facebook "Friends:" Social Capital and College Students' Use of Online Social Network Sites, Journal of Computer-Mediated Communication 12, 1143-1168.

Elmer, G., 2004, Profiling Machines, Cambridge, MA: MIT Press.

ENISA, 2009c, Cloud Computing - Benefits, Risks and Recommendations for the Information Security, Heraklion.

ENISA, 2009, Cloud Computing - Information Assurance Framework, Heraklion

ENISA, 2009a, Cloud Computing - SME Survey, Heraklion

ENISA, 2009b, Cloud Computing Risk Assessment, Heraklion.

Ercan, T., 2010, Effective use of cloud computing in educational institutions, Procedia Social and Behavioral Sciences 2(2), 938-942.

Erdogmus, H., 2009, Cloud Computing: Does Nirvana Hide behind the Nebula?, IEEE Software 26(2), 4-6.

Etro, F., 2009, The Economic Impact of Cloud Computing on Business Creation, Employment and Output in Europe. An application of the Endogenous Market Structures Approach to a GPT innovation, Review of Business and Economics 54(2), 179-208.

Ferdig, R. E., Dawson, K., Black, E. W., Black, N. M. P. and Thompson, L. A., 2008, Medical students' and residents' use of online social networking tools: Implications for teaching professionalism in medical education, First Monday 13(9).

Fielder, A. et al., 2012, Cloud Computing, Berlin.

Foster, I., Zhao, Y., Raicu, I. and Lu, S., 2008, Cloud computing and grid computing 360degree compared, Grid Computing Environments Workshop 2008, Austin, TX.

Fraser, M. and Dutta, S., 2008, Throwing Sheep in the Boardroom: How Online Social Networking Will Transform Your Life, Work and World. Hoboken et al.: Wiley.

Friedewald, M., Georgieff, P.,andJoepgen, M., 2001, Application Service Providing Software mieten statt kaufen, FB/IE - Zeitschrift für Unternehmensentwicklung und Industrial Engineering 50 (6), 265-267.

Fuchs, C., 2009, Social Networking Sites and the Surveillance Society. A Critical Case Study of the Usage of studiVZ, Facebook, and MySpace by Students in Salzburg in the Context of Electronic Surveillance, Salzburg/Wien: ICT\&S Center (University of Salzburg), Forschungsgruppe Unified Theory of Information.

Fuchs, C., 2010, Facebook, Web 2.0 und ökonomische Überwachung, Datenschutz und Datensicherheit (DuD) (7), 453-.458.

Gartner Inc., 2010, Gartner Says Worldwide Cloud Services Market to Surpass $\$ 68$ Billion in 2010, Gartner Newsroom, June 2010 <http://www.gartner.com/it/page.jsp?id=1389313>.

Gartner Inc., 2012, Gartner Says Cloud Adoption in Europe Will Trail U.S. by At Least Two Years, Stamford/Mass., June 2012 <http://www.gartner.com/it/page.jsp?id=2032215>.

Granovetter, M. S., 1973, The Strength of Weak Ties, American Journal of Sociology 78(6), $1360-1380$.

Grawrock, D., 2006, The Intel Safer Computing Initiative. Intel Press.

Gross, R. and Acquisti, A., 2005, Information Revelation and Privacy in Online Social Networks (The Facebook case), in: Atluri, V., De Capitani di Vimercati, S. and al. 
(Eds): Proceedings of the 2005 ACM Workshop on Privacy in the Electronic Society, WPES 2005, Alexandria, VA, USA, November 7: ACM Press, 71-80.

Hargittai, E., 2007, Whose Space? Differences Among Users and Non-Users of Social Network Sites, Journal of Computer-Mediated Communication 13(1), 276-297.

Häusler, S., 2007, Soziale Netzwerke im Internet. Entwicklung, Formen und Potenziale zu kommerzieller Nutzung, Saarbrücken: VDM Verlag Dr. Müller.

Heidemann, J., 2010, Online Social Networks - Ein sozialer und technischer Überblick., Informaktik-Spektrum 33 (2010), 262-271.

Heiser, G., Andronick, J., Elphinstone, K., Klein, G., Kuz I. and Ryzhyk, L., 2010,The Road to Trustworthy Systems. Communications of the ACM, 53(6), 107-115, June, 2010.

Hoffa, C., Mehta, G., Freeman, T., Deelman, E., Keahey, K., Berriman, B., Good, J. and 2008, On the Use of Cloud Computing for Scientific Workflows, Fourth IEEE International Conference on eScience, 7-12 December 2008, Indianapolis.

Hoffman, E. S., 2009, Evaluating Social Network Tools for Distance Learning, TCC 2009 Proceedings, 92-100.

IBM Institute for Business Value, 2008, Value 2.0. Eight new rules for creating and capturing value from innovative technologies, Somers, New York.

Infoworld, 2011, The 10 worst cloud outages (and what we can learn from them). Sending your IT business to the cloud comes with risk, as those affected by these 10 colossal cloud outages can attest. http://www.infoworld.com/d/cloud-computing/the-10worst-cloud-outages-and-what-we-can-learn-them-902. June 27, 2011.

Kobyliński, A. and Michalski, M., 2011, Cloud Computing and Economic Growth in the Baltic Sea Region Countries, Perspectives in Business Informatics Research 90(7), 296303.

Koch, M. et al., 2009, Enterprise 2.0: Planung, Einführung und erfolgreicher Einsatz von Social Software in Unternehmen, Oldenbourg.

Kroes, N. SPEECH/11/50, 2011, Towards a European Cloud Computing Strategy, World Economic Forum Davos, 27 January 2011, Brussels.

Kroes, N. SPEECH/12/38, 2012, Setting up the European Cloud Partnership, World Economic Forum Davos, 26 January 2012, Brussels.

Kushida, K. E., Murray, J. and Zysman, J., 2011, Diffusing the Cloud: Cloud Computing and Implications for Public Policy, Journal of Industry, Competition and Trade 11(3), 209-237.

Lack, C., Beck, L. and Hoover, D., 2009, Use of social networking by undergraduate psychology majors, First Monday 14(12).

Lehavot, K., 2009, MySpace or Yours? The Ethical Dilemma of Graduate Students' Personal Lives on the Internet, Ethics \&Behavior 19(2), 129-141.

Leimbach, T. and Wydra, S., 2010, Competitiveness Index for the European Software and IT services industry, Karlsruhe.

Leskovec, J. and Horvitz, E., 2008, Worldwide buzz: Planetary-scale views on a large instant-messaging network, in: Proceedings of the 17th international conference on World Wide Web, April 21-25, Beijing, 915-924.

Levitt, R., 2011, Toward Project Management 2.0, CRGP Working Paper \#0066, Stanford.

Levy, M., 2009, WEB 2.0 implications on knowledge management, Journal of Knowledge Management, 1 (2009), 120 - 134.

Lewis, K., Kaufman, J. and Christakis, N., 2008, The Taste for Privacy: An Analysis of College Student Privacy Settings in an Online Social Network, Journal of ComputerMediated Communication 14(1).

Liebenau, J., Karrberg, P., Grous, A. and Castro, D., 2012, Modelling the Cloud. Employment effects in two exemplary sectors in The United States, the United Kingdom, Germany and Italy, London: LSE-Enterprise.

Lilischkis, S., 2011, Policies in support of high-growth innovative SMEs. INNO-Grips Policy Brief No. 2. June 2011. Version 1.5.

Livingstone, S., 2008, Taking risky opportunities in youthful content creation: teenagers' use of social networking sites for intimacy, privacy and self-expression, New media \& society $10(3), 393-411$. 
Marston, S., Li, Z., Bandyopadhyay, S., Zhang, J. and Ghalsasi, A., 2011, Cloud computing-The business perspective, Decision Support Systems 51(1), 176-189.

McAfee, A., 2006, Enterprise 2.0: The Dawn of Emergent Collaboration. MIT Sloan Management Review 47(3).

McFredries, P., 2008, Technically speaking: The cloud is the computer, IEEE Spectrum 45(8), 20.

Mell, P. and Grance, T., 2011, The NIST Definition of Cloud Computing (Draft), January: National Institute of Standards and Technology.

Milgram, S., 1967, The small world problem., Psychology Today 2(1), 60-67.

Myerson, J., 2009, Cloud computing versus grid computing. Service types, similarities and differences, and things to consider, IBM, March 3 <http://www.ibm.com/developerworks/web/library/wa-cloudgrid/>.

Nentwich, M. and König, R., 2012, Cyberscience 2.0. Research in the Age of Digital Social Networks; in series: Interactiva, Vol. 10, edited by Bieber, C., Leggewie, C. and Lobin, H., Frankfurt/New York: Campus.

Falliere, N., O Murchu, L., Chien, E., 2011, W32.Stuxnet Dossier, Symantec.

O'Reilly, T., 2005, What Is Web 2.0. Design Patterns and Business Models for the Next Generation of Software, O 'Reilly, May $30<$ http://oreilly.com/web2/archive/what-isweb-20.html>.

Osimo, D. et al., 2010, Enterprise 2.0 study - D4 Final report, Brussels.

Paquette, S., Jaeger, P. T. and Wilson, S. C., 2010, Identifying the security risks associated with governmental use of cloud computing, Government Information Quarterly $27(3), 245-253$.

Parallels Inc., 2012, Parallels SMB Cloud Insights Global Model, Renton (WA) $<$ http://www.parallels.com/de/smbreport/>.

Pearson, S., 2009, Taking Account of Privacy when Designing Cloud Computing Services, 2009. http://www.hpl.hp.com/techreports/2009/HPL-2009-54.html.

Peleg, D., 2000, Distributed Computing: A Locality-Sensitive Approach, Philadelphia: Society for Industrial and Applied Mathematics.

Phillipon, T. and Veron, N., 2008, Financing Europe's fast movers, Brussels (Brueghel Policy Brief 2008/1).

Pratchett, L., Durose, C., Lowndes, V., Smith, G., Stoker, G. and Wales, C., 2009, Empowering communities to influence local decision making. Evidence-based lessons for policy makers and practioners.

Praveena, K. and Betsy, T., 2009, Application of Cloud Computing in Academia, IUP Journal of Systems Management 7(3), 50-54.

Rao, I., 2010, Yammer Debuts A Facebook For The Enterprise, TechCrunch, Palo Alto, California.

Regalado, A., 2011, Who coined the term "Cloud Computing"?, Technology Review, October 31.

Richter, A., 2010, Der Einsatz von Social Networking Services in Unternehmen. Eine explorative Analyse möglicher soziotechnischer Gestaltungsparameter und ihrer Implikationen, Heidelberg.

Richter, D. et al., 2011, Internet Social Networking - Stand der Forschung und Konsequenzen für Enterprise 2.0, Wirtschaftsinformatik, 2 (2011), 89-103.

Röll, F. J., 2010, Social Network Sites.Digitale Jugendkulturen, in: Hugger, K.-U. (Ed.): VS Verlag für Sozialwissenschaften, 209-224.

Ronzani, D., 2009, The battle of concepts: Ubiquitous Computing, pervasive computing and ambient intelligence in Mass Media, Ubiquitous Computing and Communication Journal 4(2), 9-19.

Satyanarayanan, M., 2001, Pervasive computing: Vision and challenges, IEEE Personal Communications 8(4), 10-17.

Sridhar, T., 2009, Cloud computing - A primer. Part 1: Models and technologies, The Internet Protocol Journal 12(3), 2-19.

Steinfield, C., Ellison, N. B. and Lampe, C., 2008, Social capital, self-esteem, and use of online socialnetworksites: A longitudinal analysis, Journal of Applied Developmental Psychology 29(6), 434-445. 
Sultan, N., 2010, Cloud computing for education: A new dawn?, International Journal of Information Management 30(2), 109-116.

TCS, 2012, The TCS Cloud Study, New York, 1 June <http://www.tcs.com/cloudstudy/Pages/default.aspx>.

Ristenpart,T., Tromer, E.,Shacham, H., Savage, S., 2009, Hey, you, get off of my cloud: exploring information leakage in third-party compute clouds. ACM Conference on Computer and Communications Security 2009: 199-212

Vaidhyanathan, S., 2011, The Googlization of Everything. And Why We Should Worry, Berkeley/Los Angeles: University of California Press.

Valkenburg, P. M., Peter, J. and Schouten, A. P., 2006, Friend Networking Sites and Their Relationship to Adolescents' Well-Being and Social Self-Esteem CyberPsychology\&Behavior 9(5), 584-590.

Vaquero, L. M., Rodero-Merino, L., Caceres, J. and Lindner, M., 2008, A break in the clouds: towards a cloud definition, ACM SIGCOMM Computer Communication Review 39(1), 50-55.

Veugelers, R. and Cincera, M., 2010, Young Leading Innovators and EU'S R\&D intensity gap, Seville (IPTS Working Papers 2010-07).

Veugelers, R. and Schneider C., 2008, On young innovative companies: why they matter and how (not) to policy support them, Leuven.

Wanhoff, T., 2011, Wa(h)re Freunde - Wie sich unsere Beziehungen in sozialen OnlineNetzwerken verändern, Heidelberg: Spektrum Akademischer Verlag.

WEF, 2011, Exploring the Future of Cloud Computing - Riding the Next Wave of Technology-Driven Transformation, Davos.

Weiser, M., 1991, The computer for the 21st century, Scientific American 265(3), 94-104.

Wimmer, J., 2009, The Publics behind Political Web Campaigning. The Digital Transformation of 'Classic' Counter-Public Spheres, in: Baringhorst, S., Kneip, V. and Niesyto, J. (Eds): Political Campaigning on the Web, Bielefeld: transcript, 31-51. 


\section{ANNEX: PROJ ECT PLAN “CLOUD COMPUTING AND SOCI AL NETWORKS"}

\section{Project phases in detail}

With the submission of this interim report, the consultation phase of the STOA-project "Cloud Computing and Social Networks" (Phase 1) has been finalised. The purpose of this consultation phase was to sharpen the concept of the project, outline and substantiate the research questions and, based on preliminary insights, develop a detailed project plan.

In the following, the objectives of the next four phases of the project will be described. In addition, an overview of the planned activities, deliverables and the timing of the project will be presented.

\section{Phase 2: Foundations of Cloud Computing}

Based on the initial overview prepared in the consultation phase, the overall aim of this phase is to analyse the technological, economic and legal foundations of cloud computing. This includes the evolution of the technology and the current state of services based on it, as well as an analysis of driving factor and barriers for the take-up of cloud computing in Europe.

The phase encompasses two parallel work packages, which require close co-ordination due to the interrelations in some points. The work will be based on desk research as well as consultations with leading experts in the different fields. Moreover the consortium will also actively seek co-operation with interested MEPs.

WP 1: Evolution of cloud computing technology and concept

In order to shape the understanding of cloud computing it is necessary to research and analyse the evolution of cloud computing technologies and concepts, since the idea behind it has a rather long tradition that can be traced back to the 1960s. This also includes a review of technological requirements necessary for a broad diffusion of it. In a second step a robust description and definition of existing technologies and services as well as an analysis of their differences and similarities will take place.

Main tasks:

- $\quad$ Analysing the evolution of the cloud computing technology

- Describing examples of existing cloud computing technologies as well as representative current services based on the technology

Analysis of the technological requirements (network capacity, technical measures for storage etc.) for a diffusion (today/future)

Outlook on possible future technological developments 
WP 2: Driving factors or barriers for cloud computing in Europe

Complementary to the technological evolution and state of the art of cloud computing, this work package is aimed at analysing the current cloud computing environment. In a first step this includes an overview of the current market for cloud services internationally the structure of the relevant industries. Different layers of services will be distinguished, making the difference between basic infrastructure layers ( such as Google docs for instance ) and value added services that can be added on top of it ( such as document management for business for instance ) In a second step we will - based on the existing literature - identify the most important driving factors and barriers for the uptake of cloud computing in Europe. In a final step we will analyse and assess the identified factors.

Main tasks:

- $\quad$ Providing an overview of the current market situation (including suppliers and their locations)

- Identifying major factors driving or hindering the current evolution of cloud computing

o technological factors (e.g. standards)

o economical/business factors

o social/cultural factors (e.g. acceptance of technology)

o legal factors (e.g. regulations related to data protection)

Analysing and assessing the identified factor

The results of both WP will be compiled in one report.

\section{Phase 3: I mpacts of cloud computing on society and economy}

Based on the previous work, the goal of this phase is to analyse the economic and social impacts of cloud computing. Further specifications may also come from STOA or will be developed as suggestions in the course of phase 1 . It consists of two parallel work packages, each dealing with a specific part of impacts. The rationale behind this split into general economic and social impacts on the one hand and especially impacts in the field of customer rights, privacy and security on the other is that the importance of the latter, which is also reflected in the public debate and research, requires an in-depth analysis. However, the close connection of both areas requires a tight co-ordination and co-operation between both and will lead to a common draft conclusion paper.

The desk research in phase 2 will be complemented by a workshop that will bring together leading stakeholders from industry, civil society, and academia as well as interested MEPs to discuss and validate the preliminary findings and recommendations of this phase.

The expected outcome of this phase is an analysis of the economic and social impacts of cloud computing in the form of two working papers, and a set of preliminary recommendations for European decision-makers on the issues at stake.

WP3: Economic and social impacts of cloud computing

This work package is aimed at an identification and analysis of general economic and social impacts of cloud computing in Europe. In a first step it will analyse the direct impact caused 
by cloud computing on the IT services, as well as on the software and Internet markets and industry in Europe. One important point in the course of this part of the analysis is the impacts on existing structures of the industry. In a second step the direct impact on others, i.e. private business, public authorities, science and innovation system and private households, will be identified and analysed in close co-operation with WP4. This includes also an analysis of impacts on the structure and organization in these areas. In a third step it will give an overview of indirect impacts on society and economy based on the existing literature. Finally, options for action on view of the developments in America and Asia will be developed.

Main tasks:

- Identifying and analysing direct impacts on the software and IT services industry/market

- Identifying and analysing direct impacts on private business, public authorities, science and innovation system, and private households

- $\quad$ Analysing indirect impacts on economy and society (growth, job creation etc.)

The results of both WP will be compiled in one report.

WP 4: Security, privacy, intellectual property/copyright and other legal issues of cloud computing

Given the high importance of questions related to privacy and security threats in the case of cloud computing it seems important to perform an in-depth analysis of these questions, including their legal aspects. In three strands we will address the problems of customer rights related to the use of cloud services, the challenges to governance arising from it as well as technical aspects of security, privacy, and intellectual property/copyright protection in cloud computing services. All this will be analysed in detail and in relation with the parallel work package (WP3).

Main tasks:

Researching technical issues and options

o security threats and related protection measures in the cloud (confidentiality, availability, integrity)

o intellectual property/copyright protection

o Technical options

o Research issues

Researching customer rights in the cases of:

o unavailability of services

o loss or corruption of data

o data breach, loss of sensitive information

o breach of protection of intellectual property/copyright

Analysing governance issues

o Process, storage and delivering in countries with different legislations

o international harmonisation of legislation on cloud computing

o international enforcement of legislation

o responsibility for security problems 


\author{
o Auditing requirements \\ o Contractual issues \\ Options for EP action
}

\title{
Phase 4: Social Networks
}

Given the specific context and issues of Social Networks, this topic will be treated in two extra modules which are independent from the others, but at the same time co-operates with them whenever possible. For example, when legal aspects such as consumer rights are tackled in the main project, these results might be relevant for Social Networks, too. In this way, it will be possible to account for the specific issues of this field, but also to benefit from work in the other workgroups. The modulescovering Social Networks Sites (SNS) on the one hand and on the other hand Enterprise Social Media Services will be designed along the research questions of the main project, but adapted where necessary. To guarantee a close linkage, both will be intertwined during the consultation and the final reporting phase. However, there will be also a set of specific research questions related to both that will be addressed in both parts of the modules.

WP 5: Social Network Sites

(1) In a first step the module will review the different types of SNS focusing on the one hand on the general-purpose SNS, such as Facebook or Google+, and more specific professional SNS, such as LinkedIn, XING, VZ group or ResearchGate, on the other hand. The study will analyse the differences of usage of general and professional SNS. Based on existing studies the module will seek to identify motivations for the use of SNS. In a further step, also risks related to this extensive usage by young people will be explored. Building upon this review of cultural and social factors the module will also analyse legal implications arising from that situation. In further steps technological and economic factors like the different types of business models (membership, data exploitation, in-shop-concepts, etc.) or alternative technological approaches like Diaspora will be researched. This will also include an assessment of the identified factors as well as an outlook to direct and indirect impacts of SNS for the economy and society as a whole.

(2) The second part of the module will explore societal impacts with a particular focus on privacy and security aspects. Based on these, regulatory issues and related policy options will be discussed.. Also here are some specific issues and threats that differ between SNS and cloud computing. For example consumer rights in the case of unavailability will not have the same importance for general-purpose SNS as opposed to professional SNS, while especially questions related to the deployment of data protection and privacy will have much more importance due to the public character of some SNS. Therefore the module will review these points. This analysis will be a major input for the workshop at the European Parliament. The goal of this workshop is to discuss policy options for the EP with all relevant stakeholders. Therefore MEPs, representatives of the European Commission, experts and researchers as well as representatives of the industry (Facebook, XING, etc.) will be invited. 
Main tasks:

- Providing an overview on the current state-of-the-art of SNS (including suppliers and their locations)

- Identifying major factors shaping the current evolutionof SNS:

o technological factors (e.g. standards)

o economic factors

o social/cultural factors (e.g. attitudes towards privacy issues)

o regulatory factors (e.g. regulations related to data protection, intellectual property and copyright, security obligations, etc.)

- $\quad$ Analysing and assessing the identified factors

- $\quad$ Analysing direct and indirect impacts on economy and society

- Researching technical options and issues, such as privacy-by-design, customer rights and governance challenges related to SNS

\section{WP 6: Web based enterprise Social Software Services}

This module will address the emerging segment of restricted business oriented social networks like Yammer, Communote and other services categorized as enterprise software. The underlying functions like micro-blogging, networking and collaboration are essential parts of the Enterprise 2.0 (E2) concept, which evolved in the mid of the 2000s. The basic idea of E2 was to exploit the benefits of social software for improving communication and collaboration within enterprises. In the following several enterprises like for example BT (British Telecom) as an early adaptor implemented own solutions. Also many enterprise software producers like IBM, SAP or Oracle subsequently started to implement features in their own systems. However in the recent years enterprises like Yammer or Communote appeared offering solutions as web-based services addressing two major challenges: Firstly the need of especially small and medium sized companies, which are not able or willing to implement enterprise systems offered by IBM; SAP or others. Secondly it also addressed the limitations of such systems, which formed a barrier for the integration of suppliers or customers using different systems.

Based on that these services form an interesting combination of both aspects, cloud computing as well as social network sites, which we deal with in the previous phases of the project. Given that the topic will be treated in an extra module which is independent from the others, but at the same time co-operates with them whenever possible. For example, when legal aspects such as compliance and regulatory aspects are tackled in the part on cloud computing, these results might be relevant for web-based enterprise social software services. On the other side aspects specific in the context of SNS like intellectual property rights the results might be relevant here as well. In this way, it will be possible to account for the specific issues of this field, but also to benefit from work in the other workgroups. The module will be designed along the research questions of the main project, but adapted where necessary. To guarantee a close linkage, it will be intertwined during the consultation and the final reporting phase.

In a first step the module will review the underlying concepts and identify and analyse the market for enterprise social software tools based on existing literature. In the following an 
in-depth review of the market and innovation potentials of business social networks will take place. This includes an analysis of the motivations as well as barriers for using the different types of services. In a following step implications of the implementation and usage of such tools will be analysed. In further steps technological and economical factors like the different types of business models or alternative technological approaches will be researched. This will also include an assessment of the identified factors as well as an outlook to direct and indirect impacts of it on enterprises as well as economy and society as a whole. The final part of the module will address questions related to security, privacy, and the protection of intellectual property/copyright resulting from the use of web-based enterprise social software services, in particular regulatory/security issues linked to the processing of sensitive EU business communication through services hosted in the USA. Although there is as mentioned before a broad set of intersections on the one hand to Cloud Computing as well as on the other hand to SNS, there are some specific implications like the fact that communication in web-based enterprise social software services can contain information that are affected by existing regulations on compliance of which companies are not aware in difference to specific cloud computing applications such as human resource management. Therefore the module will review this points and set specific foci related to the web-based enterprise social software services.

The analysis of it will be also an input for the workshop organised in phase 4 at the European Parliament. The goal of this workshop is to discuss policy options for the EP with all relevant stakeholders. Therefore MEP's, representatives of the Commission, experts and researchers as well as representatives of the industry will be invited.

Main tasks:

- Providing an overview on the current market situation (including suppliers and their locations)

- Identifying major factor driving or hindering the current evolution:

o technological factors (e.g. standards)

- economical/business factors

o social/cultural factors (e.g. attitudes towards usage)

o legal factors (e.g. regulations related to data protection, intellectual property and copyright, security obligations, etc..)

- $\quad$ Analysing and assessing the identified factors

- $\quad$ Analysing direct and indirect impacts on business as well as on economy and society

Each WP will produce a report covering the results of the work.

\section{Phase 5: Reporting}

The final project phase will consist of reporting and quality control. It will include a critical internal review of the key findings and recommendations generated by the project as well as a discussion of policy options. The aim is to produce a high quality final report that will be considered useful by European decision-makers. 
Main tasks:

- $\quad$ Compiling the results of the previous phases (and the two extra modules on social network as appropriate) including a consideration of policy options

- $\quad$ Integration of workshop results and MEP comments

- Internal review

Writing final report

\section{Deliverables and dates}

The research questions which were described in the section above translate into the project plan for the project "Cloud Computing and Social Networks" in the following way.

\section{Phase 2: Foundations of Cloud Computing}

Deliverable:

- $\quad$ Report "Foundations of Cloud Computing" covering the following subjects:

o Analysis of the evolution of cloud computing concepts and technology

o Analysis of the driving factors and barriers for the development of cloud computing

o Points of tensions between the technological ease for cloud computing services facilitated by the Internet on one hand and international governance/regulatory issues on the other hand.

o Conclusions and presentation of the possible options identified.

\section{Phase 3: I mpacts of Cloud Computing on society and economy}

Deliverables:

- $\quad$ Report "Impacts of Cloud Computing" covering the following subjects:

o Analysis of economic and social impacts of cloud computing

o Analysis of Security, privacy, intellectual property/copyright and other legal issues of cloud computing

o Conclusions and presentation of the possible options identified

- Organisation of a workshop on the content of the two reports above

\section{Phase 4: Social Networks}

Phase 4 on Social Networks consist of two work packages. One dedicated to Social Network Sites and one to Enterprise Social network Services". It will last from mid of January 2013 to mid of October 2013.

Deliverables:

- $\quad$ Report "Social Network Sites" covering the following subjects:

o Overview of the different types of Social Networks Sites,

o Analysis of benefits and risks of different types of Social Network Sites, 
- Analysis of the societal impacts ofdifferent types of Social Network Sites with a particular focus on privacy and security aspects and other regulatory issues such as intellectual property/copyright and open access,

o Conclusions and presentation of the possible options identified.

- $\quad$ Report "Enterprise Social Software Services" covering the following subjects:

o Overview of the different types of Enterprise Social Software, in particular web-based solutions,

o Analysis of the driving factors and barriers for the development of web based enterprise social software services,

o Analysis of the security, privacy, intellectual property/copyright and other legal and regulatory issues ofweb based enterprise social software services,

o Conclusions and presentation of the possible options identified

- $\quad$ Organisation of a workshop on the content of the two reports above

\section{Phase 5: Final reporting}

Phase 5 of the project consists of the final reporting. It will last from mid of August 2013 until mid of December 2013.

Deliverable:

- $\quad$ Final Report

Overview of deliverables and dates

\begin{tabular}{|c|c|}
\hline Phase 2: J uly $15^{\text {th }} 2012$ - December $15^{\text {th }} 2012$ & Date of delivery \\
\hline Report "Foundations of Cloud Computing" & 15December 2012 \\
\hline \multicolumn{2}{|l|}{ Phase 3: January $15^{\text {th }} 2013-$ July $15^{\text {th }} 2013$} \\
\hline Report "Impact of Cloud Computing" & 15 July 2013 \\
\hline Workshop No. 1 "Cloud Computing" & within June 2013 \\
\hline \multicolumn{2}{|l|}{ Phase 4: J anuary $15^{\text {th }} 2013-$ October $15^{\text {th }} 2013$} \\
\hline Report "Social Network Sites" & 15October 2013 \\
\hline Report "Enterprise Social Software Services & 15September 2013 \\
\hline Workshop No. 2 "Social Networks" & within September 2013 \\
\hline \multicolumn{2}{|l|}{$\begin{array}{l}\text { Phase 5: Final Reporting August } 15^{\text {th }} 2013- \\
\text { December } 15^{\text {th }} 2013\end{array}$} \\
\hline Final Report & 15 December 2013 \\
\hline
\end{tabular}

